\title{
Online Marketing for Farming using Android
}

\author{
Radhika Baskar, S.Saleem
}

\begin{abstract}
Our nation is a developing based making country. Data spread to the learning rise agribusiness development zone is dismantle by ready to give the specialist information organizations and quick advancement of convenient correspondence. It traverses any boundary between the openness of cultivating data and transport of horticulture development yields and agribusiness system. Versatile handling, appropriated processing, AI and fragile figuring is the immerging strategies which are being used in for all intents and purposes all fields of research. Besides this, they are in a like manner important in our regular activities, for instance, guidance, remedial and agribusiness development. This undertaking inspects how Android Apps of green associations have impacted the ranchers in their creating exercises
\end{abstract}

keywords: Android studio, Java, XML

\section{INTRODUCTION}

Farmers in a general sense have a spot with natural domains, insensible about the monetary circumstances and in view of the nonappearance of concentrate related to the various business focuses overworld, they will be to sell their farmwork things in neighborhood promote. In fact, even normally buyers, dealers of farmwork things has oblivious about the arrangements, quality, sums, and obtained of dissimilar farmwork viewed collectively conveyed in each the edge of place. Perhaps industries don't have space plan shrewd to continue to neglectful their chance to buy the thing in the market. By and by each person needs to save time and money.

The key idea is, Android is to give a simple to utilize have something, to the buyers and vendors as the farmers to sell things successfully. The things open through this have something accessible to be bought will be affirmed things. This will be a shielded circumstance for online customers. The standard strategy for doing auction is so far surely understood at this point in light of its confinements a regularly expanding number of people are thinking about moving to Mobile Applications. In crucial manual closeout, there is a very set number of the general populace included. There is an open door for corruption and various components for not giving clear advertising. In relating to closeout, the days of the offer, setting and the things for deals are encouraged to the meaning populace through propose. The overall public who can wish to share in the trading ought to at first select himself and after that land at the area of the deal on the given date and time.

\section{METHODOLGY \& RESULTS}

\subsection{Introduction}

The purpose is to develop for a straightforward emptying site will be where as any kind of thing is the sold and offer some motivating force added organizations to the bidders and the sellers. The things will be affirmed and the site of gives a protected area to online industries or customers. The present structure was a modernized system. Nevertheless, it was inexpert in satisfying the building up the requirements of individuals when all is said in done. In a manual deal, the day of closeout, setting and the things for deals are encouraged to the general populace. The all-inclusive community who wish to take an interest in the deal ought to at first enroll himself and after that meet up at the setting of the closeout on the given database like date and time.

The system limits of the charmed especially at an auction out of the city to diminish their offer or excitement as they can't be available upon the entry of closeout. Another flaw of this procedure is the stacks of work area work that must be kept up and after that keep, it set something aside for what's to come. They have to screen the especially at an auction and the traders until their last settlement. The issue with this structure is reliably the individuals uses to pass on project with them in the midst of the period of offering and the vendors needs to keep every one of the information of the individuals until an aside from if the deal system gets wrapped up. Another issue is that the deal is simply held at the area exhibit, not at the overall measurement.

\subsection{Working process:-}

Our working process will be a phone Application using which the industries (buyers) and the farmers (sellers) need to deal with everything from their phone to any territory and they don't need to go other places. This application will be open for all the natural populace, vendors, farmers, and others on Android-based phones. People from over the landmass can share in this trading. Anyone can get to this software and request for the things moved by farmers, merchants There will be full straightforwardness User endorsement and checks Our duty is a structure has be an Android request where the industries and the farmers need to deal everything their PCs from the landmass and they 
don't need to go other states and areas. It is a made the deal method direct. The customers of the structure will be industries, farmers and Administrator.

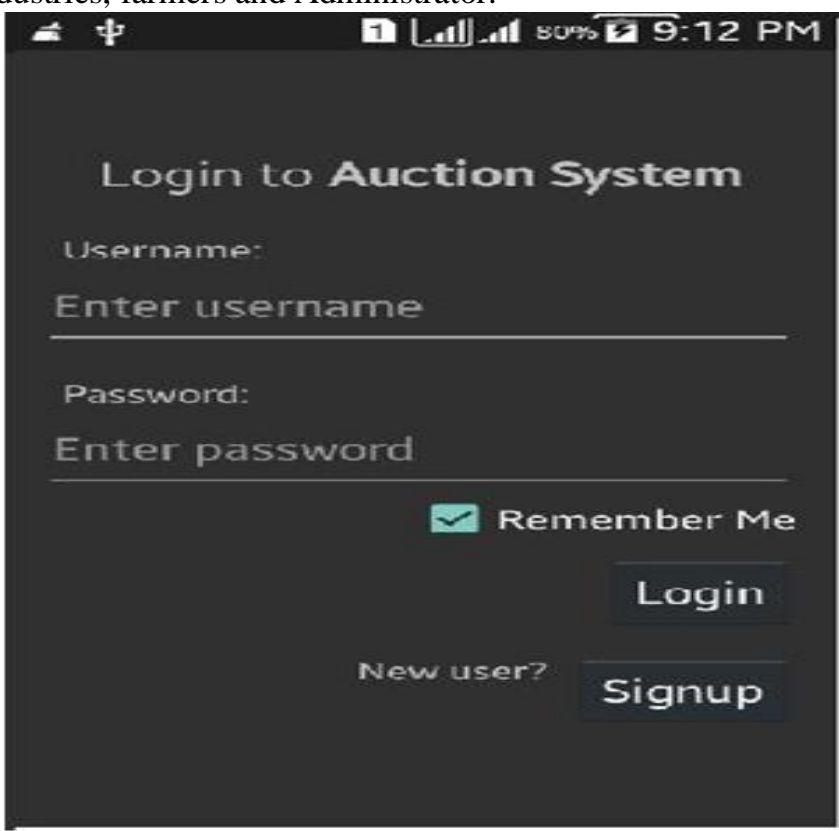

Fig 3.1 Login page for the user register

A cutting edge cultivating procedure utilizing the Android Application is given to upgrade straightforwardness. In the Agriculture ware advertise region. By giving business sector cost and Information, facilitating aggregate purchasing of data sources and aggregate selling of produce. Makers embraced the accompanying procedure to give fledgling systems to ranchers.

1.Weather forecast report

2.Data about crops

3.News and feeds

4.Farming tools and technology

Use case diagram for a modern farming techniques using android application

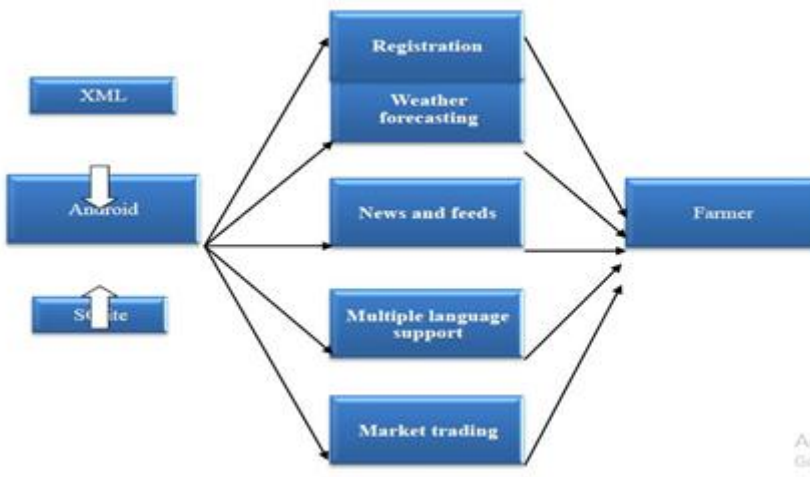

Fig 3.1.1 Structure of APPs.

On Android-based answer for Indian Agriculture the board which is to build up an Android Application to oversee Agricultural exercises those are doing on a day by day, week by week and month to month premise in the ranch.

Android-based answer for Indian Agriculture the executives works in the accompanying strides to make a profile of rancher, homestead, and yield in that ranch.

[1] Weather information on the basis of village registered.
[2] Prepare financial budgets and monitor its execution.

[3] Keep records for all assets of farm (fields, machines, raw-materials).

[4] Maintain expenditure record.

[5] Generate revenue on the basis of expenditure record and income generated.

[6] Information of different government of india scheme for indian farmers.

[7] Get access to pesticides, fertilizers and seed databases

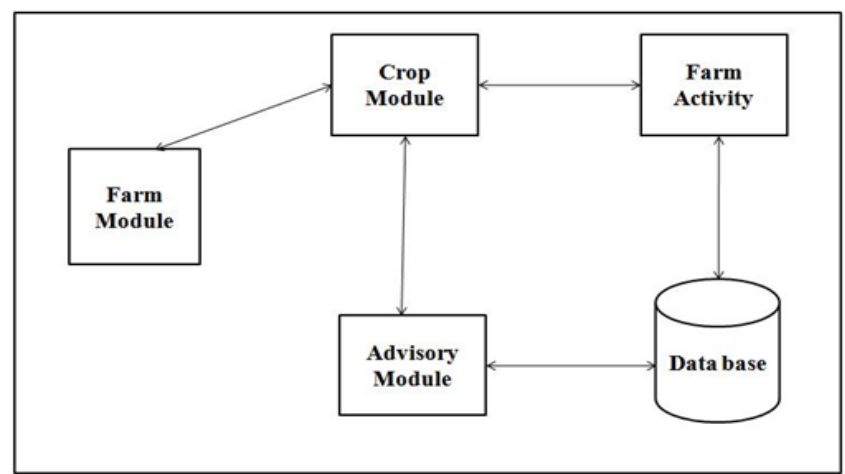

Fig 3.1.2 Working of Android-based answer for Indian Agriculture Management

Consequence of Android-based answer for Indian Agriculture the executives is an Android-based arrangement For Indian Agriculture the board which will be helpful to give an answer for Indian Agricultural administration to improve their harvest yield. The Application would be an advantage to the Indian ranchers. As it Addresses the key issues of getting the market updates of various items.

An Android Application for farmers to disperse agribusiness information is to familiarize this system is to give the blooms, verdant sustenance's nuances information (such as soil, compost, methodology for gathering, etc.) to the farmer in voice structure, free of cost, at whatever point, wherever using Android propelled cell phone without web get to.

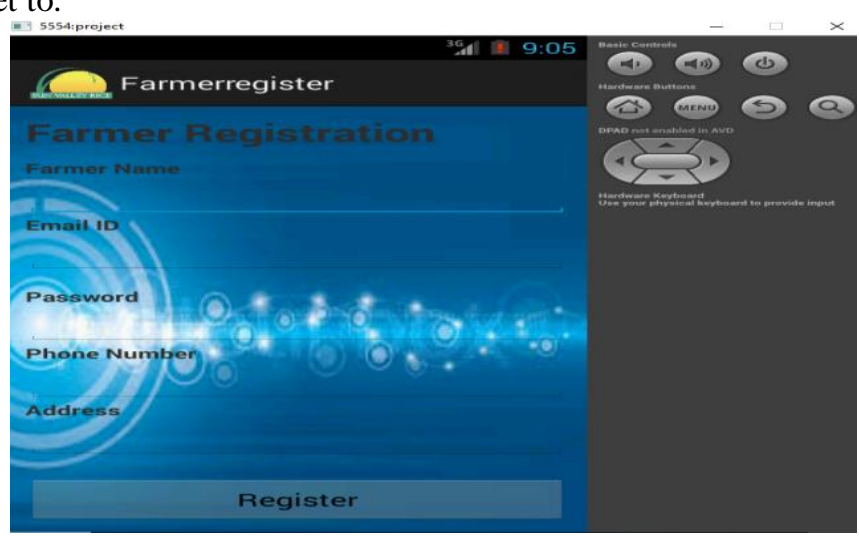

Fig 3.2 Register page:

In the page, anyone can be pick or login page for this application. In the registration the help for client details and baffle key of up to least five character and symbols. In case the client isn't marked in, by then client should enroll on it.

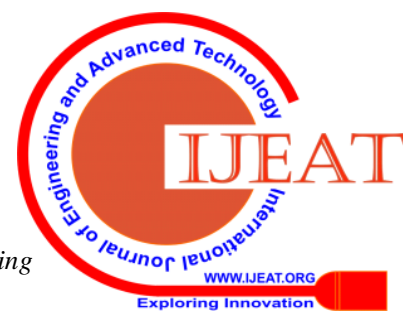




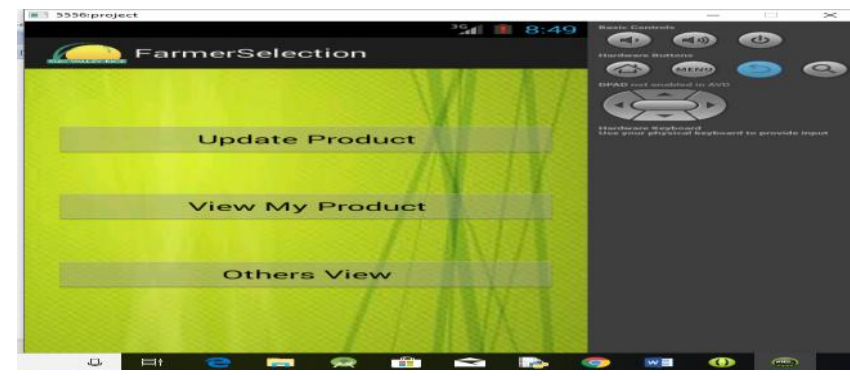

Fig 3.3 List view of items:

In the course list points of view on all in all errand. The greeting page involves the login page. The make closeout will made by the dealer when the will farmers posting the things for emptying.

\subsubsection{Industries page:-}

In this page, the vendor will add the thing information data wherein if needs to sell or closeout the thing through on the web. In this pages the shipper can be post of the image of the thing by the catch picture and each and every the basic inform about the thing, for instance, the thing name of farmer, its delineation and the closeout on the date and the time at what the thing will be emptied ultimately the stop

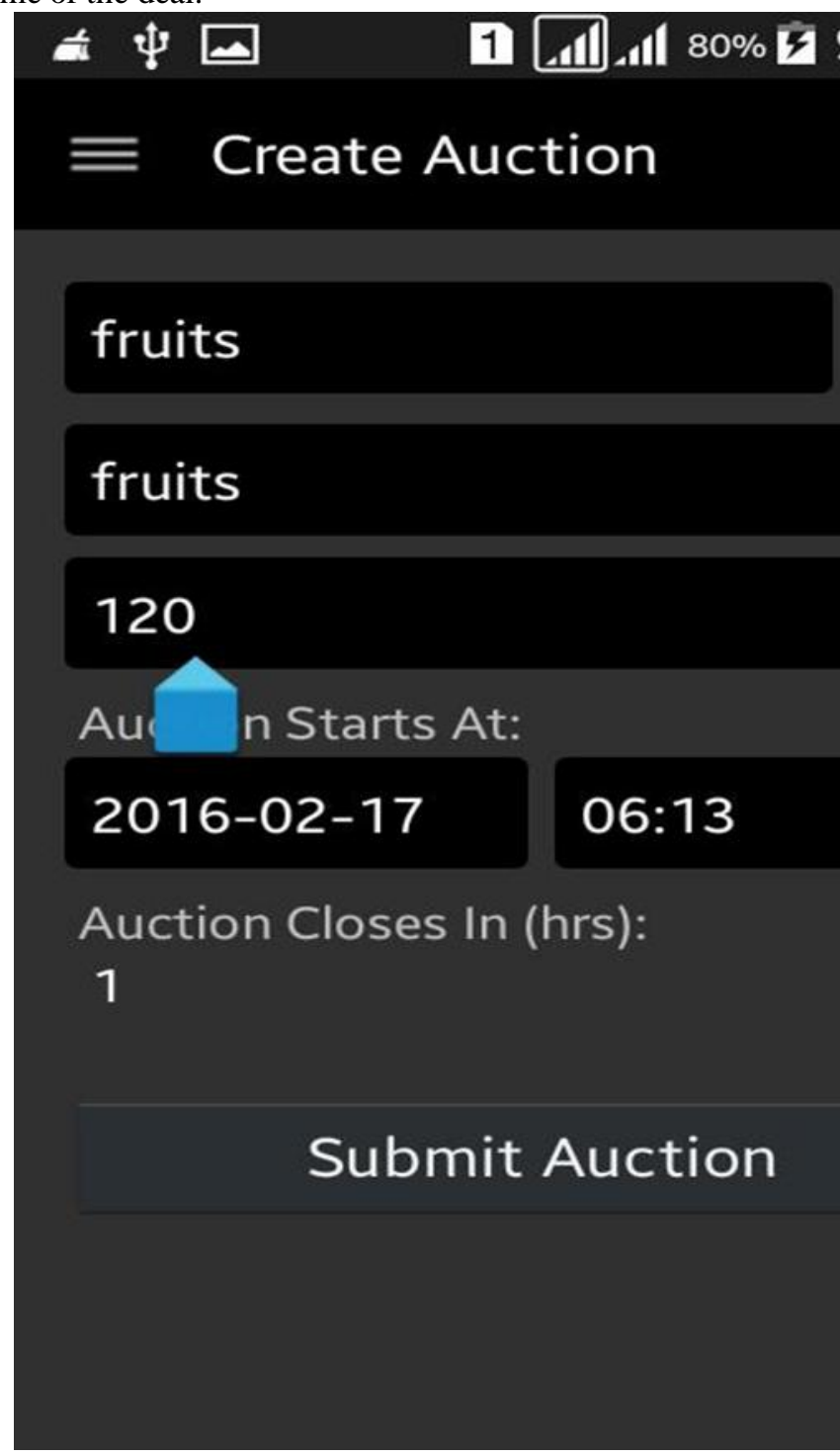

Fig 3.4 Farmer page while creating the auction time of the deal.

\subsubsection{Industries page:-}

In this pages the industries will at first see which thing is being posted on the application which is to be sold. The farmers and industries will see every one of the database of information about the thing. In an occasion that the bidder is interested to buy that thing, at that the point he can select for the emptying and offer the aggregate. At long last, at the completion of the emptying, the bidder will turn out to be more on familiar with the result. Last when the amount of offer has been made by the bidder will pick the whole which thing to be closeout. The industries needs to sell inside a period which is collection of the farmer while making closeout then is an everyday.

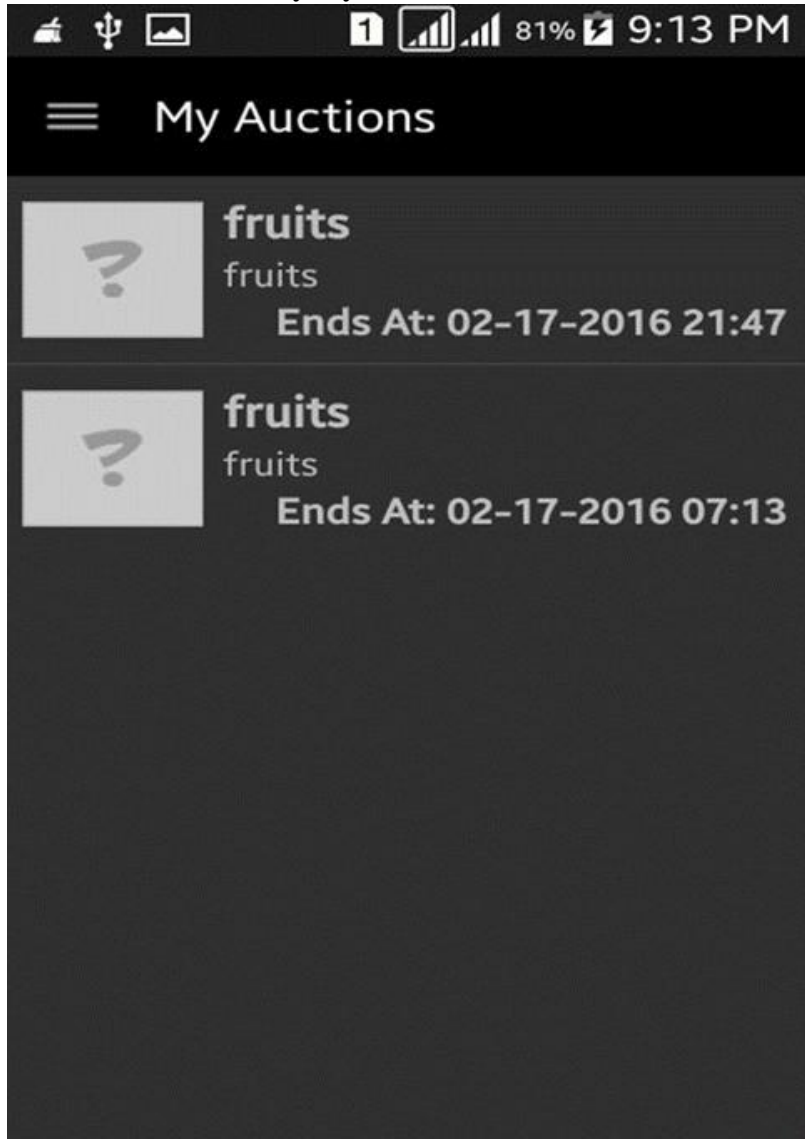

Fig 3.5 Bidder will see the things nuances that have been presented accessible on be obtained

\section{CONCLUSION}

For the most part, we give a simple to utilize emptying page where the kind of thing will be sold and offer some advantage added organization to the bidders and shippers. In the essential time of our endeavor, we have made two pages. Our first page is the endorsement of an executive. In the second page, we give the selection to the farmer and industries. On the possibility that the authoritatively selected, by then, the customer can direct login page to the closeout site and the director can on the general database on the customers. Last time of the assignment requirement delivery process on this, where the victor of the industries will be getting his things passed on through suitable marketing trades.

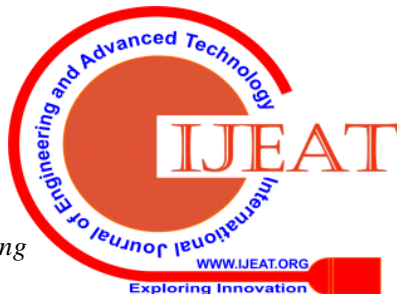




\section{REFERENCES}

1. CassadyR.Jr. "Sell-offs and unloading" University of California.

2. Bajari, Patrick, Ali Hortacsu (2004). "Monetary Insights from Internet of Auctions" Journal of Economic Literature, Vol. XLII No. 2: 457-86.

3. Lucking-Reiley, David (2000), "Sell-offs Agri-on the Internet: What's Being Auctioned, and How? "Diary of Industrial Economics, 48(3):227- 52.

4. S Subramanian 1998 "Structure and check of secure electronic auction"proceedings of IEEE Symposium on solid circulated framework.

5. EngelbrechtAndWiggans R. "Sell-offs and Bidding Models a study" Cowles establishment and dialog paer no.486R.

6. Toyama, Renee Kuriyan, SavitaBailur, NimmiKentaroRangaswamy,AishwaryaRatan, Rajesh Veeraraghavan, Deepak Menon, Joyojeet Pal, JankiSrinivasan,"Review of the Research on the Rural PC Kiosks"

7. K-RIAD Kiosk for Rural India Agriculture Development -Farmer to E-farmer-T.V. Subhramanyam, K. Satish, Y.K. Viswanadham-(IJERT), 6, August 2012

8. UC Division of Agriculture and Natural Resources Explore Health Kiosk Project by Mike Poe - At University of California 